\title{
The language-like behavior of Lana chimpanzee: Is it merely discrimination and paired-associate learning?
}

\author{
JAMES L. PATE and DUANE M. RUMBAUGH \\ Language Research Center of Georgia State University, Atlanta, Georgia \\ and Yerkes Regional Primate Research Center of Emory University, Atlanta, Georgia
}

\begin{abstract}
The productions of Lana chimpanzee during an experiment that lasted 25 days were analyzed from a "stock sentence" approach and from a phrase-structure approach. In answering questions posed by the experimenter and in making requests, Lana's productions seemed to be best explained in the phrase-structure approach, in which phrases, rather than individual lexigrams, served as lexical units. Phrases were transposed, both correctly and incorrectly, and were combined to convey different meanings. Thus, it was concluded that Lana's productions require a more complex model than the simple discrimination learning model suggested by Thompson and Church (1980).
\end{abstract}

Recently, Thompson and Church (1980) argued that at least one data block of the language-like behavior of Lana chimpanzee (Rumbaugh, 1977) could be explained, for the most part, in terms of conditional discriminations and paired-associate learning. A discrimination among six "stock" sentences and a choice of an appropriate lexigram as the paired associate of something in Lana's environment accounted for $91 \%$ of her sentences when the experimenter was present and $66 \%$ of her sentences when the experimenter was absent. Obviously, if all of Lana's productions can be explained in this rather simple way, language-like behavior remains just that, language-like behavior.

Since Lana was trained to use the system by being taught "stock" sentences, it is not surprising that much of her early behavior in the language-learning project can be accounted for in this way. These "stock" sentences, which Lana had been taught explicitly, serve as frames into which other units (lexigrams in this case) can be placed. But the number of "stock" sentences is of some importance in that if the number necessary to account for her behavior is very large, then the idea of a "stock" sentence loses its value; that is, if the number of frames becomes excessively large, it can be argued that the "stock"

This research was supported by grants from the National Institute of Child Health and Human Development (HD-06016) and from the Division of Research Resources, National Institutes of Health (RR-00165). A preliminary report of these findings was presented at the meeting of the Southeastern Psychological Association in New Orleans, March 1982. Requests for reprints should be directed to James L. Pate or Duane $M$. Rumbaugh, Department of Psychology, Georgia State University, Atlanta, Georgia 30303. sentence approach is not the simplest explanation of the behavior. Furthermore, although in the early stages of the research Lana was taught in a "stock sentence" framework, in later stages she was not.

In addition to the number of stock sentences, the variety of choices within a "stock" sentence must be considered. In the Thompson and Church (1980) study, the most variable "stock" sentence, S5, involved a choice among only four verbs. If the number of choices at a point or the number of choice points is increased substantially, again the concept of a "stock" sentence loses its meaning. Both the number of "stock" sentences and the number of choices must be considered because they are not independent. Rather, the data can be viewed as containing (1) many "stock" sentences with a few choices or (2) fewer "stock" sentences with more choices. From our perspective, it is not the absolute number of either the "stock" sentences or the choices but, rather, the number of combinations, particularly the ones formulated by Lana with apparent appropriateness, which is important.

A second question concerns the usefulness of the Thompson and Church (1980) approach in an expanded language system. In 1976, the computer system was changed to allow Lana to use more than seven lexigrams in a single production. If Lana was discriminating only among "stock" sentences, which she had been taught in early training, and selecting appropriate paired associates, it would seem unlikely that she would employ the expanded system spontaneously, and yet she did (Pate, Rumbaugh, \& Betz, Note 1). Even though she was not taught "stock" sentences containing more than seven lexigrams, a limit for the earlier system, the Thompson and Church (1980) approach could still be employed 
if longer frames that were filled in a variety of ways could be identified.

\section{METHOD}

Lana's productions on 25 days (July 13, 1977, to August 29, 1977) during question-answering periods were analyzed. In this experiment, Lana was asked a series of questions about the name of a food or drink, the container in which the food or drink was placed, and its location. After answering these questions correctly, Lana was asked whether she wanted the food or drink. Typically, she answered "yes" immediately. She was then required to ask that the food or drink be brought into her room if it was outside her room. Finally, she had to ask that the food or drink be given to her. Her responses to these questions are the data analyzed in this experiment. It should be noted that, since other experiments were being conducted and since her normal interchanges with the computer and humans continued to occur, Lana's responses constituted only a relatively small proportion of her productions on the days this experiment was conducted. Further details regarding the computer-controlled language keyboard that Lana employed are provided elsewhere (Rumbaugh, 1977).

Each sentence was classified as being syntactically and lexically correct (well-formed), syntactically incorrect, lexically incorrect, or incomplete. For each sentence, the first error determined the classification among the three error categories. For example, if the first error in a sentence was a syntactic error, then the sentence was classified as a syntactic error even if lexical errors occurred later in the sentence or even if the sentence was incomplete. Unfortunately, for a few of the sentences, a word was not recorded by the computer system. For some of these sentences, the experimenter's response provided information about Lana's response. For example, if the transcript showed " name of this" and the experimenter answered "yes," then it could be inferred that Lana had used the correct lexigram for the name of the food or drink. Sentences with missing words for which no inference could be made $(n=18)$ were excluded from the remainder of the analysis. The well-formed sentences were classified into several groups of similar (stock) sentences, and their frequencies were tabulated. Sentences in the three error categories also were classified and tabulated.

\section{RESULTS}

In a set of 881 sentences, 512 were well formed, 108 were incomplete, 196 were syntactically incorrect, 47 were lexically incorrect, and 18 could not be classified because a lexigram was not recorded by the computer and no clear inference was possible. Each category of sentences was analyzed separately.

The 512 well-formed sentences were found to consist mainly of sentences containing one of three stems, "name of this," "Question you," and "Lana want." These sentences are shown in Tables 1, 2, and 3. Sentences shown in Table 1 all contained "name of this" as a stem, but it should be emphasized that there were 14 different "stock" sentences. For the first position of a sentence containing "name of this," there was a choice among five consumables, with the consumable shown to Lana differing from day to day. (In four cases, all involving Sentence 1, Lana named correctly a container, a box, rather than a consumable.) Thus, even though the sentences in Table 1 may be considered "stock" sentences, there
Table 1

Sentences With “Name This” as a Stem.

\begin{tabular}{|c|c|c|}
\hline $\begin{array}{l}\text { Sentence } \\
\text { Number }\end{array}$ & Sentence & Frequency \\
\hline 1 & {$\left[\left(^{*}\right)\right.$ name this]. } & 27 \\
\hline 2 & [(*) name this] [in (\$)]. & 39 \\
\hline 3 & {$[(*)$ name this] [in (\$)] $[(+)$ room $]$. } & 12 \\
\hline 4 & [(*) name this] [that's in (S)]. & 17 \\
\hline $\begin{array}{l}5 \\
6\end{array}$ & $\begin{array}{l}\text { [(*) name this] [that's in }(\$)][(+) \text { room] } \\
\text { [Banana name this] [that's in cup] }\end{array}$ & 25 \\
\hline & [that's in room]. & 2 \\
\hline 7 & {$\left[\left({ }^{*}\right)\right.$ name this $][(+)$ room $]$} & 35 \\
\hline 8 & {$\left[\left({ }^{*}\right)\right.$ name this] $[(+)$ room $][$ in $(\$)]$. } & 18 \\
\hline 9 & [(*) name this] [that's $(+)$ room]. & 19 \\
\hline 10 & $\begin{array}{l}\text { [Sweet potato name this] [that's out room] } \\
\text { [in bowl]. }\end{array}$ & 1 \\
\hline 11 & {$\left[\left({ }^{*}\right)\right.$ name this] [that's $\left.(@)\right]$} & 24 \\
\hline 12 & $\begin{array}{l}\text { [Sweet potato name this] [that's orange] } \\
\text { [in (\$)]. }\end{array}$ & 3 \\
\hline 13 & $\begin{array}{l}\text { [Sweet potato name this] [that's orange] } \\
\text { [in room]. }\end{array}$ & 2 \\
\hline 14 & $\begin{array}{l}\text { [Juice name this] [that's purple] [in box] } \\
\text { [in room]. }\end{array}$ & 1 \\
\hline
\end{tabular}

Note:* = juice, milk, M\&M, banana, sweet potato; $\$=$ cup, bowl, box, machine; + = in, out of, behind; and = green, orange, red.

are 14 of them. Furthermore, in some there was a choice among three sets of paired associates; Lana had to choose one of five consumables (juice, banana, M\&M, milk, sweet potato), one of three containers (box, cup, bowl), and one of three locations (in, out of, or behind her room). Thus, ignoring other difficulties, the fifth sentence in the list, even if it is considered a "stock" sentence to be filled with paired associates, is rather complex in that there were $\mathbf{4 5}$ possible combinations of paired associates that could have been used to fill the "stock" sentence, with 25 of these combinations being employed in this experiment.

Another view of the data in Table 1 is that the productions are language-like in that lexigrams were combined to produce phrases which, in turn, were combined to produce sentences. Accepting this view, phrases were marked with brackets and tabulated. The first phrase, " $\left({ }^{*}\right)$ name of this," occurred at the beginning of each of these sentences but not at the beginning of all sentences, as will be seen in subsequent tables. The phrase, "in (\$)" occurred 74 times, and a variant of the phrase, "that's in $(\$), "$ where $\$$ represents a consumable, occurred 44 times. The phrase "+room," where + represents in, out of, or behind, occurred 93 times, and its variant occurred 22 times. In addition to the stem, which occurred 225 times, the phrase, "that's @," where @ represents a color, occurred 30 times. Thus, the analysis into phrases indicates that the 225 sentences were composed of 6 phrases arranged in different orders.

The variation in ways of stating the container or location is rather important in that the addition of 
"that's" is a grammatical aspect called "insertion." According to Stalke (1980), one would not expect insertions to occur if Lana's behavior were following a strict finite-state grammar.

There are 29 "stock" sentences in Table 2 and 17 "stock" sentences in Table 3. For the sentences in Tables 2 and 3, there is a greater variety of "stock" sentences than in Table 1. Furthermore, for some sentences, there were four sets of paired associates among which Lana had to choose, with the fourth set involving a choice among four verbs (carry, give,

Table 2

Sentences With "Question You" as the Stem.

\begin{tabular}{|c|c|c|}
\hline $\begin{array}{l}\text { Sentence } \\
\text { Number }\end{array}$ & Sentence & requency \\
\hline 1 & [Question you carry Lana]. & 7 \\
\hline 2 & [Question you carry Lana] [( +) room]. & 5 \\
\hline 3 & [Question you move $(+)$ room]. & 24 \\
\hline 4 & [Question you give $\left(^{*}\right)$ ]. & 4 \\
\hline 5 & [Question you (**) $\left(^{*}\right)$ ] [in (\$)]. & 21 \\
\hline 6 & [Question you (**) (*)] [that's in (\$)]. & 6 \\
\hline 7 & [Question you (**) (*)] [in (\$)] [( + ) room]. & 15 \\
\hline 8 & [Question you (**) (*)] [that's in (S)] & \\
\hline & {$[(+)$ room $]$. } & 14 \\
\hline 9 & $\begin{array}{l}\text { [Question you }(* *)(*)][\text { in }(\$)][(+) \text { room] } \\
\text { [to Lana]. }\end{array}$ & 4 \\
\hline 10 & $\begin{array}{l}\text { [Question you (**) (*)] [that's in }(\$)] \\
{[(+) \text { room] [to Lana]. }}\end{array}$ & 2 \\
\hline 11 & $\begin{array}{l}\text { [Question you carry sweet potato] } \\
\text { [that's in cup] [to Lana]. }\end{array}$ & 1 \\
\hline 12 & $\begin{array}{l}\text { [Question you }(* *)(*)][\text { in }(\$)] \text { [to Lana] } \\
{[(+) \text { room]. }}\end{array}$ & 7 \\
\hline 13 & $\begin{array}{l}\text { [Question you }(* *)(*)] \text { [that's in }(\$)] \\
\text { [to Lana] }[(+) \text { room]. }\end{array}$ & 19 \\
\hline $\begin{array}{l}14 \\
15\end{array}$ & $\begin{array}{l}\text { [Question you }(* *)(*)][(+) \text { room]. } \\
\text { [Question you carry banana] }\end{array}$ & 7 \\
\hline & [that's in room]. & 1 \\
\hline 16 & $\begin{array}{l}\text { [Question you (**) M\&M] [behind room] } \\
\text { [in box]. }\end{array}$ & 2 \\
\hline 17 & $\begin{array}{l}\text { [Question you give banana] } \\
\text { [that's in room] [in box]. }\end{array}$ & 1 \\
\hline 18 & $\begin{array}{l}\text { [Question you }(* *)(*)][(+) \text { room] } \\
\text { [to Lana] [in }(\$)] .\end{array}$ & 2 \\
\hline $\begin{array}{l}19 \\
20\end{array}$ & $\begin{array}{l}\text { [Question you (**)(*)] [to Lana]. } \\
\left.\text { [Question you }\left(^{* *}\right)(*)\right] \text { [to Lana] } \\
{[(+) \text { room]. }}\end{array}$ & 4 \\
\hline 21 & $\begin{array}{l}\text { [Question you give banana] [to Lana] } \\
\text { [behind room] [in box]. }\end{array}$ & 1 \\
\hline $\begin{array}{l}22 \\
23\end{array}$ & $\begin{array}{l}\left.\text { [Question you }\left(^{* *}\right)(*)\right] \text { [to Lana] [in (\$)]. } \\
\text { [Question you }\left(\left(^{* *}\right)\left(\left(^{*}\right) \text { ] [to Lana] [in }(\$) \text { ] }\right.\right.\end{array}$ & 15 \\
\hline 24 & $\begin{array}{l}\text { [(+) room]. } \\
\text { [Question you put sweet potato] }\end{array}$ & 16 \\
\hline $\begin{array}{l}25 \\
26 \\
27\end{array}$ & $\begin{array}{l}\text { [that's orange] [in bowl]. } \\
\text { [Question you give box of M\&M] [in room]. } \\
\text { [Question you give (\$) or (*) [to Lana] [in room] } \\
\text { [Question you carry M\&M] [into room] }\end{array}$ & n]. $\begin{array}{r}1 \\
1\end{array}$ \\
\hline & [to Lana] [in room]. & 1 \\
\hline 28 & $\begin{array}{l}\text { [Question you carry sweet potato] } \\
\text { [that's in bowl] [out room] [in room]. }\end{array}$ & 1 \\
\hline 29 & $\begin{array}{l}\text { [Question you give Lana] [M\&M] [in box] } \\
\text { [in room]. }\end{array}$ & 1 \\
\hline
\end{tabular}

Note: " = juice, milk, M\&M, banana, sweet potato; $\$=$ cup, bowl, box, machine; $+=$ in, out of, behind; and ${ }^{* *}=$ move, carry, put, give.
Table 3

Sentences With "Lana Want" as the Stem.

\begin{tabular}{|c|c|c|}
\hline $\begin{array}{l}\text { Sentence } \\
\text { Number }\end{array}$ & Sentence & Frequency \\
\hline 1 & [Lana want sweet potato]. & $\Gamma$ \\
\hline 2 & [Lana want $(*)$ ] [in (\$)]. & 3 \\
\hline 3 & [Lana want ] [that's in bowl]. & 1 \\
\hline 4 & [Lana want $\left.\left(^{*}\right)\right][(+)$ room] & 3 \\
\hline \multirow[t]{2}{*}{$\begin{array}{l}5 \\
6\end{array}$} & [Lana want banana] [that's in room]. & 1 \\
\hline & [in machine]. & 1 \\
\hline 7 & [Lana want $(\%)(*)]$ & 2 \\
\hline 8 & [Lana want eat $(*)][$ in $(\$)]$. & 8 \\
\hline 9 & [Lana want eat (*)] [that's in (\$)]. & 4 \\
\hline \multirow{3}{*}{$\begin{array}{l}10 \\
11\end{array}$} & [Lana want eat $\left.\left(^{*}\right)\right][$ in $(\$)][(+)$ room]. & 3 \\
\hline & [Lana want eat sweet potato] & \\
\hline & [that's in bowl] [out room]. & 1 \\
\hline 12 & $\begin{array}{l}\text { [Lana want eat banana] [that's in cup] } \\
\text { [that's in room]. }\end{array}$ & 1 \\
\hline \multirow[t]{2}{*}{$\begin{array}{l}13 \\
14\end{array}$} & $\begin{array}{l}\text { [Lana want eat sweet potato] [behind room]. } \\
\text { [Lana want eat sweet potato] }\end{array}$ & 1 \\
\hline & [that's in room]. & 1 \\
\hline 15 & $\begin{array}{l}\text { [Lana want eat banana] [behind room] } \\
\text { [in box]. }\end{array}$ & 1 \\
\hline 16 & $\begin{array}{l}\text { [Lana want eat sweet potato] } \\
\text { [that's orange]. }\end{array}$ & 1 \\
\hline 17 & $\begin{array}{l}\text { [Lana want eat sweet potato] [that's orange] } \\
\text { [in bowl] [in room]. }\end{array}$ & 1 \\
\hline
\end{tabular}

Note: = juice, milk, M\&M, banana, sweet potato; $\$=$ cup, bowl, box, machine; $+=$ in, out of, behind; and $\%=e a t$, drink.

put, move). Again the more language-like view can be taken, and the phrases in Tables 2 and 3 are marked with brackets. In addition to a different stem or beginning phrase, Lana used two additional phrases, "to Lana" and "into room," in the sentences in Tables 2 and 3.

Sentences that did not contain one of the common stems are shown in Table 4. Three of these sentences are "stock" sentences from Thompson and Church (1980). Considering all 512 of the well-formed sentences, 67 "stock" sentences were used. Clearly, the demands of the discrimination task here, to use the Thompson and Church (1980) approach, are substantial, and the formation by Lana of sentences from phrases seems to be a more reasonable alternative perspective.

The sentences in Tables 1,2 , and 3 were compared for similarity of content in different structural forms. Consider Sentences 2 and 4 or 3 and 5 in Table 1 as examples. Even though the content is precisely the same, the structure is slightly different; one would not expect such appropriate insertions to occur so frequently by chance, or at all, if a finite-state grammar were structuring Lana's behavior. Furthermore, phrases may be viewed as complex units, and they, rather than the lexigrams, seem to be reordered to produce synonymous statements, as in Sentences 3 and 8. On the assumption that it would be inefficient to have more than one "stock" sentence for conveying one set of information, using different 
Table 4

Other Sentences Without a Common Stem.

\begin{tabular}{lc}
\multicolumn{1}{c}{ Sentence } & Frequency \\
\hline Yes. & 51 \\
Juice in cup. & 1 \\
M\&M in box $(+)$ room. & 2 \\
You put M\&M in box. & 1 \\
Please machine make slide. & 1 \\
Please machine make window open. & 1 \\
Please machine give M\&M in room. & 1 \\
\hline
\end{tabular}

Note: $+=$ in, out of, behind.

structures should not be expected. However, there are numerous examples of structurally different sentences with the same semantic content. Obviously, with longer sentences, there are more possibilities for structural variation. Sentences $3,5,6,8$, and 10 are essentially synonymous, and Sentences 3,5 , and 8 occurred very frequently. In fact, it would seem that Lana should have used Sentence 3 on the 61 occasions when she used Sentences $3,5,6,8$, and 10 , since it is the simplest "stock" sentence. If Lana were merely discriminating among "stock" sentences, it would be difficult to construct an explanation of why she used five different stock sentences to convey the same information.

A second major factor in the Thompson and Church (1980) approach is the choice of a lexigram that is a paired associate of something in Lana's environment. When the number of sets of paired associates was small, and when the sets contained only a few alternatives, the explanation was useful. However, here the number of sets is often four, and the number of elements in a set may be as high as five. Thus, the number of combinations is exceedingly large, with a maximum of 135 combinations, and their individual correctness is contingent upon the conditions of the paradigm extant at a given time. Another problem with the paired-associate approach concerns the associate for the lexigram. So long as the lexigrams were being paired only with tangible objects in Lana's environment, the learning of the paired associate seemed straightforward. However, in the present situation, Lana had to choose among lexigrams for objects (milk, juice, sweet potato, M\&M, banana, box, bowl, cup) and those for nonobjects (in, out of, behind, move, carry, give, put). Thus, it is difficult to invoke the paired-associate concept to explain Lana's choice of one of these verbs or relational words.

Of the 108 incomplete sentences, 18 began with " ( $\left.{ }^{*}\right)$ name," 45 began with "Question you," and 11 began with "Lana want." In addition, there were 33 one-word productions, and one production began with "Sweet potato out." Since either the experimenter or Lana could terminate a string, no further analysis of these incomplete sentences was made.
Various types of syntactic errors are shown in Table 5 . Some errors could not be classified or were unique occurrences. Some lexigrams in Yerkish were appropriate only in the first position of a sentence, and the occurrence of such lexigrams in other positions resulted in the immediate termination of that string, a first-word error. In some strings, Lana pressed the same lexigram successively, yielding a repeatedword error. In some strings, Lana omitted a lexigram or misused a lexigram, with "where" and "do" being the most commonly misused symbols. Intrusion errors, those produced by placing a phrase incorrectly in a sequence or adding a phrase to a string that would have been correct had the string been terminated, were by far the most common errors made by Lana. Of the 196 syntactically incorrect sentences, 81 were a result of intrusions. It should be noted that this was an error type that appeared at the time the system was expanded to allow longer strings. Although the errors have continued to occur, their frequency has been much lower than it was immediately after the expansion.

Sentences with lexical errors occurred relatively infrequently and involved naming a consumable incorrectly, naming a container incorrectly, or giving the location of the consumable incorrectly. There were very few lexical errors of any other type.

Table 5

Sentences With Syntactic Errors.

\begin{tabular}{|c|c|}
\hline Error Type & Frequency \\
\hline Unclassifiable & 33 \\
\hline First-word error & 7 \\
\hline Repeated word & 39 \\
\hline Missing word within a sentence & 8 \\
\hline Missing word at the beginning of a sentence & 4 \\
\hline Misuse of "where" & 14 \\
\hline Misuse of "do" & 8 \\
\hline Intrusions of "into room" & 13 \\
\hline (") name this into room. & 8 \\
\hline (*) name this into room in (\$). & 2 \\
\hline$(*)$ name this that's in (\$) into room. & 3 \\
\hline Intrusions of "to Lane" & 70 \\
\hline (") name this to Lana. & 12 \\
\hline (") name this in (\$) to Lana. & 6 \\
\hline (*) name this to Lana in (\$). & 16 \\
\hline Sweet potato name this to Lana in room. & 1 \\
\hline $\begin{array}{l}\text { (') name this behind room to Lana. } \\
\text { Sweet potato name this that's orange to Lana. }\end{array}$ & $\begin{array}{l}2 \\
3\end{array}$ \\
\hline (") name this that's in (\$) to Lana. & 13 \\
\hline (") name this that's in room to Lana. & 2 \\
\hline Sweet potato name this that's orange to Lana & \\
\hline in room. & 1 \\
\hline Sweet potato name this to Lana in room in box. & 1 \\
\hline $\begin{array}{l}\text { (") name this }(+) \text { room to Lana in cup. } \\
\text { Sweet potato name this that's out room to Lana }\end{array}$ & 2 \\
\hline in $\ldots$ & 1 \\
\hline (*) name this that's in (\$) to Lana in room. & 8 \\
\hline
\end{tabular}

Note- = juice, milk, M\&M, banana, sweet potato; $\$=$ cup. bowl, box, machine; and $+=$ in, out of, behind. 


\section{DISCUSSION}

Thompson and Church (1980) argued convincingly that in the early stages of the language-learning project Lana's language-like behavior could be explained readily in terms of simple discrimination among "stock" sentences combined with paired-associate learning. However, with the present analyses, it is shown that although some productions may still be explainable in these simple terms, others pose considerable difficulty. With the expansion of the control system allowing more than seven lexigrams in a string, the possibility of "stock" sentences accounting for all of Lana's productions was reduced markedly.

Although recognizing that we cannot prove that Lana is not using "stock" sentences in combination with the choice of an appropriate paired associate, the present corpus seems to pose considerable difficulty for such an approach. Conservatively, it can be suggested that Lana was choosing among 69 different sentences, rather than among 6 as in the Thompson and Church (1980) study, with some of them having as many as 135 alternatives for various blanks in the "stock" sentence. Even if this explanation of her behavior is accepted, it must be conceded that her performance is rather remarkable. Furthermore, it should be noted that only a small proportion of Lana's productions during the 25 days of the experiment were included in this analysis. With a larger corpus, it could be anticipated that more "stock" sentences would be required to account for her behavior.

The view that Lana learned to make phrases from lexigrams and to use those phrases to construct sentences gains support from at least two kinds of data presented in this report. First, one of the most common syntactical errors involved the intrusion of a phrase such as "to Lana," "to Lana in room," or "into room." A single word was misplaced infrequently in comparison with phrases, and thus, it seems likely that phrases were serving as lexical units. Second, there were many examples of different structures with the same meaning. These examples usually involved the rearrangement of phrases, indicating again that the phrase is a lexical unit.

Some sentences such as " $\left({ }^{*}\right)$ name this" occurred with high frequency and thus could be called "stock" sentences. However, the number of sentences that occurred only once in this entire experiment is substantial, and if infrequent sentences are tabulated, the number is quite high. Thus, it would seem that even if Lana is using some "stock" sentences, she is also generating some unique sentences.

The Thompson and Church (1980) approach assumes that Lana's language-like behavior involves something akin to a finite-state grammar, which is known to be incapable of accounting for human language. As shown in the present analyses, the "stock" sentence explanation rendered by Thompson and Church (1980) is not sufficient for the corpus analyzed here, and even a finite-state grammar may not be sufficient for explaining Lana's behavior.

Perhaps the most convincing argument against the "stock" sentence explanation is the presence of paraphrases in Lana's productions. As shown in many of the tables, Lana used a variety of forms for conveying the same information or for making the same request. These variations could be called paraphrases, and it seems most unlikely that in a simple discrimination task the organism would paraphrase spontaneously.

In conclusion, it has been argued that Lana's language-like behavior, in later stages of training, is more than the selection of a "stock" sentence with blanks being filled by an appropriate choice of a paired associate. We do not hold that her behavior exhibits all of the characteristics of language, but the simple discrimination learning approach taken by Thompson and Church (1980) is not sufficient. Lana's productions were too complex for such a restricted model; they should be viewed as further along the behavioral continuum that ultimately supports the complexities of human language. Just where her productions should be marked on that continuum is not now clear. To do so will require a much more complete understanding of the requisites to and the processes of first language skills.

\section{REFERENCE NOTE}

1. Pate, J. L., Rumbaugh, D. M., \& Betz, S. Can a chimpanzee answer questions? Manuscript submitted for publication.

\section{REFERENCES}

RumbAUGH, D. M. (Ed.). Language learning by a chimpanzee: The Lana project. New York: Academic Press, 1977.

StalkE, H. F. W. On asking the question: Can apes learn language? In K. E. Nelson (Ed.), Children's language (Vol. 2). New York: Gardner Press, 1980.

Thompson, C..R., \& Church, R. M. An explanation of the language of a chimpanzee. Science, 1980, 205, 313-314.

(Manuscript received September 30, 1981; revision accepted for publication August 31, 1982.) 